\title{
High density, early maturing, and morphometrically unique Hippocampus erectus population makes a Bahamian pond a priority site for conservation
}

\author{
Heather Masonjones ${ }^{1, *}$, Emily Rose ${ }^{1,2}{ }^{,}$Jessica Elson $^{1}$, Breann Roberts ${ }^{1}$, \\ Jocelyn Curtis-Quick ${ }^{3}$ \\ ${ }^{1}$ University of Tampa, Tampa, Florida 33596, USA \\ ${ }^{2}$ Texas A \& M University, College Station, Texas 77843, USA \\ ${ }^{3}$ Cape Eleuthera Institute, Eleuthera, The Bahamas
}

\begin{abstract}
Anchialine pond habitats are frequently associated with biota that can differ dramatically from nearby coastal systems. In this study, we investigated lined seahorses Hippocampus erectus by season, size, and sex across a tidal lake on the island of Eleuthera (The Bahamas). In total, 35 benthic transects of 30-60 $\mathrm{m}^{2}$ were established around the lake margin and assessed 4 times between 2014 and 2016. Seahorses were mapped along each transect and photographed for morphological analyses. Mean $( \pm \mathrm{SE})$ landscape-level seahorse density was $0.14 \pm 0.013$ ind. $\mathrm{m}^{-2}$ (max. 0.66 ind. $\mathrm{m}^{-2}$ ), which was substantially higher than worldwide seahorse mean density. Local seahorse density differed both seasonally and spatially, $40 \%$ higher in the wet than dry season, and $48.8 \%$ lower in the south than in the north end of the lake. Sex-ratio was significantly male-biased in both the north end of the lake and during the wet months. Male mating effort varied seasonally and spatially, with a significantly higher frequency of gravid males in the dry season and the north end of the lake. Male seahorses were significantly larger than females, with additional morphological traits that indicate broader sexual dimorphism. Compared to other seahorse species, Sweetings Pond animals have a higher population density, smaller size at maturity, and a different shape than other $H$. erectus, indicating a population that is a discrete management unit. Given the CITES Appendix II listing of all seahorses and their decreasing numbers worldwide, this population represents a valuable biological resource that should be managed uniquely.
\end{abstract}

KEY WORDS: Seahorse $\cdot$ Mating ecology $\cdot$ Population dynamics $\cdot$ Sex ratios $\cdot$ Anchialine $\cdot$ Insular population $\cdot$ Eleuthera $\cdot$ The Bahamas

\section{INTRODUCTION}

Opportunities to study speciation in the wild are rare, but often begin by locating a geographically isolated population. Anchialine habitats are tidal saltwater bodies fed from the ocean through cracks and underground conduits (Holthuis 1973) and are well documented for supporting speciation and endemic populations (Humphreys et al. 2009, Becking

*Corresponding author: heather.masonjones@gmail.com et al. 2013, Dawson 2016). In these isolated systems, animals often shift in body size from open populations, displaying either 'giantism' or 'nanism', depending on their evolutionary history and the selective forces acting on them (Gould \& MacFadden 2004, Losos \& Ricklefs 2009, Lomolino et al. 2013). Sweetings Pond on the island of Eleuthera (The Bahamas) is a large anchialine habitat, $1.6 \mathrm{~km}$ long by $0.8 \mathrm{~km}$ wide, with a maximum depth of $13.3 \mathrm{~m}$.

() The authors 2019. Open Access under Creative Commons by Attribution Licence. Use, distribution and reproduction are unrestricted. Authors and original publication must be credited. 
Species diversity in the lake is low compared to surrounding marine systems (17 species from 15 families in the lake, 126 species from 50 families offshore), and except for a few larger fish that were stocked in the lake in the late 1970s, all invertebrate and vertebrate fauna are small, with few predators observed (Aronson 1985). Finally, both the behavior and densities of brittle stars Ophiothrix oerstedii and octopus Octopus brierus inside the lake are extremely unusual, with significantly higher densities and diurnal behavior patterns observed compared to conspecifics outside the lake (Aronson \& Harms 1985). All lines of evidence suggest that the lake is biologically isolated from the ocean, with the exception of microscopic organisms travelling through the porous limestone.

Sweetings Pond is inhabited by an unusual population of seahorses, originally described as the longsnout seahorse Hippocampus reidi (Aronson 1985). However, Rose et al. (2016) identified morphological characteristics that overlap with the sympatric lined seahorse $H$. erectus, while some features appear unique relative to both species. Lake seahorses have shorter tails compared to the torsos of $H$. erectus found in other regions (Rose et al. 2016). In spite of their membership in different evolutionary subclades separated by millions of years, $H$. reidi and $H$. erectus readily hybridize in captivity, producing viable $\mathrm{F}_{1}$ hybrids (Teske et al. 2004, Ho et al. 2015, Han et al. 2018). To date, no evidence exists for wild hybrids of these 2 species. Given the overlap of their native ranges, the potential existed for this population to be $H$. erectus, $H$. reidi, a wild hybrid, or a new species. With the use of mitochondrial (cytochrome $b$ ) and nuclear genes (S7) to resolve the species, research determined that although lake animals differ significantly in shape and size from both possible parent species, Sweetings Pond seahorses genetically cluster with $H$. erectus (Rose et al. 2016).

In addition to a potential speciation event in this unusual lake population of seahorses, syngnathid fishes (seahorses and pipefish) are of critical conservation concern. All 42 species of seahorse are listed on the IUCN Red List (Lourie et al. 2016, Short et al. 2018), and international trade in seahorses is limited through their Appendix II status under CITES (Convention on International Trade in Endangered Species). Many causes of seahorse decline exist worldwide, including habitat loss, changes in predator density, decreases in water quality, and overfishing due to increasing demands for seahorses in traditional medicines and the aquarium trade (Vincent 1996, Foster \& Vincent 2004, Martin-Smith \& Vincent
2005, Hughes et al. 2009, Harasti et al. 2014a). The most significant threats to populations of syngnathids globally comes from their uncontrolled capture as bycatch in the shrimp fishing industry and bottom trawling (Baum et al. 2003, Baum \& Vincent 2005). Few populations of syngnathids escape the impact of this widespread and devastating fishing pressure, which emphasizes why protecting this unique Bahamian seahorse population is so critical (Bell et al. 2003, Martin-Smith \& Vincent 2005). H. erectus itself is identified as Vulnerable in the IUCN Red List (www.iucnredlist.org/details/10066/0). This isolated lake population represents a potential new management unit; thus, understanding the species' unique biology is critical to successful long-term management. In addition, new pressures on this population are developing. With ecotourism increasing as the site becomes publicized, rapidly expanding agriculture along the pond edge, and evidence of harvesting seahorses, octopus, crabs, and other animals, there is increasing pressure to protect the site at the national level.

Knowledge of wild population dynamics for $H$. erectus is limited and largely based on trawl data. Populations across its range have been described as extremely low density (0.0008 ind. $\mathrm{m}^{-2}$, Florida Bay, Florida, USA, Powell et al. 2002; 0.00036 ind. $\mathrm{m}^{-2}$, Tampa Bay, Florida, Masonjones et al. 2010; 0.0098 ind. $\mathrm{m}^{-2}$, Northern Gulf of Mexico, Florida, Stallings et al. 2014), even for seahorses, which have a mean density of $0.06 \pm 0.021$ for all species (Correia et al. 2018, H. Masonjones \& E. Rose unpubl. data). This low density has been attributed to the large number of trawls that did not contain seahorses, providing landscape-level densities rather than local population densities (Baum et al. 2003). No studies have investigated temporal or spatial population dynamics in the wild on a smaller scale for $H$. erectus, with all previous studies using large-scale trawls to collect species information. Observed sex ratios have been mostly female-biased for this species, when reported (males:total $=0.38$, Teixeira \& Musick 2001; 0.42 Baum et al. 2003; 0.56 Dunham 2010), with males significantly larger than females in 3 of 4 studies available (Teixeira \& Musick 2001, Baum et al. 2003, Dunham 2010, Anderson 2012). Most seahorse species observed to date have even to femalebiased sex ratios and are monomorphic (Foster \& Vincent 2004, Moreau \& Vincent 2004, H. Masonjones \& E. Rose unpubl. data).

This initial survey of a novel anchialine system aimed to determine the extent of the shallow water distribution of seahorses, focusing on the region of 
the lake with the most vegetation. The majority of seahorses studied to date prefer habitats with ample benthic structure (Harasti et al. 2014b, Gristina et al. 2015, Correia et al. 2018, Woodall et al. 2018). We investigated whether seahorse densities in Sweetings Pond were greater than those observed in other seahorse populations worldwide, predicting that densities would be elevated if few predators inhabited the wave-sheltered site. Although octopus are known predators of seahorses and are present in Sweetings Pond, octopus densities have decreased $40 \%$ in the last $34 \mathrm{yr}$, and few other seahorse predators exist in the system (Aronson 1985, Harasti et al. 2014a, H. Masonjones et al. unpubl. data). In addition to the density assessment, we describe the distribution of seahorses by size, sex, and reproductive condition across the watershed, to determine whether this unusual, isolated population of $H$. erectus exhibits sexual size dimorphism or distribution patterns different from those observed in seahorses found in other regions. Finally, we present evidence of a larger trend in morphological relationships related to the unique features of this population first presented in Rose et al. (2016).

\section{MATERIALS AND METHODS}

\subsection{Study area}

The study location was a tidal saltwater lake located on the island of Eleuthera, The Bahamas (Fig. 1). Field research was conducted with approval from the Bahamian government through the BEST Commission (Bahamas Environment, Scientific, Technology; separate approvals for 20142016). In addition, all animal use protocols described were approved under University of Tampa AUP \#2018-1.

Across seasons, the lake demonstrated a typical subtropical marine system (see Table 1). For each sampling event, the following environmental parameters were measured: salinity (Vee Gee A366ATC refractometer), air and water temperatures $\left({ }^{\circ} \mathrm{C}\right)$, nitrite $(\mathrm{ppm})$, nitrate $(\mathrm{ppm}$; Tetra Easy Strips test strips), pH (Hanna pHep pH meter), surface and midwater turbidity (NTU, Oakton T100 turbidity meter), and phosphate (ppm; Hanna Instruments HI 713-25). GPS coordinates of transects and environmental samples were recorded with a Garmin 78sc. Transect depths were taken at both ends (HawkEye H22FX) and ranged from $0.6-5.9 \mathrm{~m}$, with a mean $( \pm \mathrm{SD})$ depth sampled of $1.93 \pm 1.04 \mathrm{~m}$.
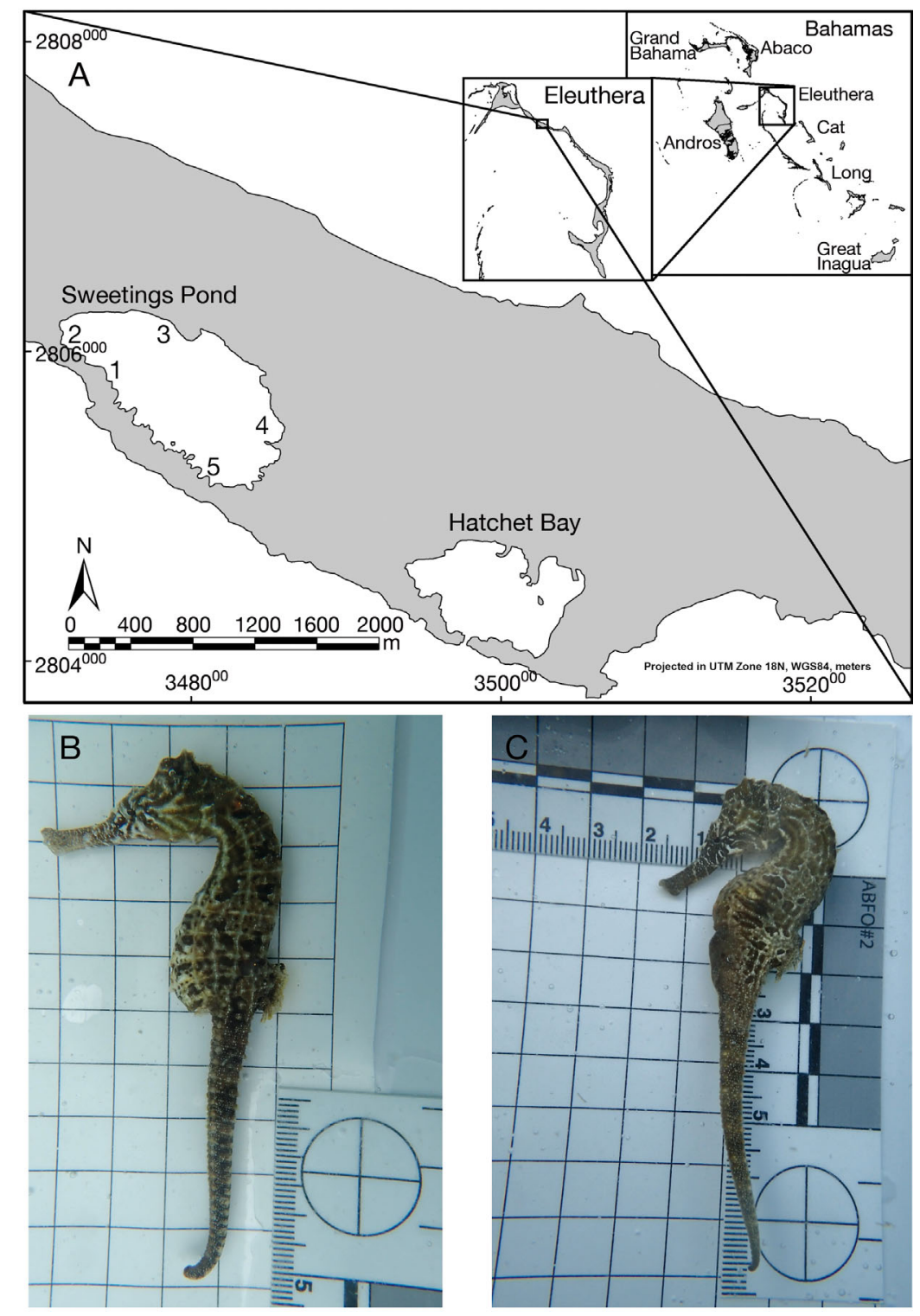

Fig. 1. (A) Location of Sweetings Pond research site $\left(25^{\circ} 21^{\prime} 40^{\prime \prime} \mathrm{N}\right.$, $\left.76^{\circ} 30^{\prime} 40^{\prime \prime} \mathrm{W}\right)$. Hatchet Bay was a similar lake to Sweetings Pond until the 1920 s, when it was opened to the ocean for conversion to a bay. Map projected in UTM Zone 18N, WGS84. 1: Control Zone; 2: Caves Zone; 3: Emmas Zone; 4: Quarry Zone; 5: Grouper Cave Zone. Zones 1-3 comprise northern location; 4-5 comprise southern location. Specimen of Hippocampus erectus

(B) female and (C) male from Sweetings Pond 


\subsection{Sampling methods}

The population biology of seahorses was assessed 4 times between 2014 and 2016, in March and July 2014, August 2015, and Feb/March 2016, and separated into wet and dry seasons (wet season: May through October; dry season: November through April). Sampling in the lake was organized into 5 zones, with 5-7 belt transects $\left(30-60 \mathrm{~m}^{2}\right)$ repeated in each zone each season, and a total area sampled of $5390 \mathrm{~m}^{2}$ across 118 transects. Within zones, transect locations were established to provide coverage of a broad range of habitat types, by pre-selecting locations on a map prior to sampling to obtain maximum spatial coverage of the region. Habitat types ranged broadly across the benthos, with $56 \%$ of area surveyed bare sediment/flocculent and other areas dominated by either algae like Laurencia spp. or Caulerpa sertularioides as dominant vegetation types (overall algae coverage $39 \%$; 9 species of algae identified). The remaining $5 \%$ was comprised of bivalve reef, corals, anemones, sponges, cyanobacteria, tunicates etc. (J. Curtis-Quick \& H. Masonjones et al. unpubl. data) and were measured during the 20142016 study period at $1 \mathrm{~m}$ intervals along $30 \mathrm{~m}$ transects using photo quadrats and 25 randomly generated points for each photo. Once at the pre-selected sampling location, a waypoint was taken and the $30 \mathrm{~m}$ transect tape was laid by swimming along the surface following a random angle from that central point. Transects sampled were limited to the shallow $(0.5-6 \mathrm{~m})$ edges of the lake due to limitations in dive tank fills on the island. In addition, during preliminary survey dives conducted as part of the benthic assessment in study planning, fewer seahorses were observed in the deeper parts of the lake where the community is dominated by bivalve reef with occasional and sparse vegetation and a maximum depth of $13.3 \mathrm{~m}$. Zones were consolidated to North (Control, Caves, Emmas) and South (Quarry, Grouper Cave) locations to investigate patterns on a gross spatial scale.

Belt width was $1 \mathrm{~m}$ during the dry season in 2014, because during the initial sampling event covering a larger area was prioritized over local distribution patterns. After the initial sampling period, belts were almost exclusively $2 \mathrm{~m}$ wide, with occasional sampling constraints such as belts that contained too many seahorses to be able to process them all on the available air. For each animal encountered in the belt, the time, their location on the transect (distance and either left or right side of tape), depth, sex (male, female, or juvenile), and reproductive status (gravid or non-gravid) were documented. Animals were photographed in situ for identification of their preferred holdfast, and then photographed against a 1 $\mathrm{cm}$ grid held in place with a piece of optically clear plexiglass to keep them in the proper orientation for consistent photographs, and finally replaced on their original holdfasts.

\subsection{Photo analysis}

Seahorses were photographed twice on each side of the body, with one photo for whole body size measurements and the second for a close-up of the head, with the minimum resolution of images being 12 megapixels. Images were used to confirm reproductive information, including sex (male, female, juvenile) and reproductive condition. Females were documented with or without orange eggs showing through the body wall, while males were either with or without embryos, with rough embryo stage indicated by either orange showing through the pouch wall (early gravid) or eyespots showing through the pouch wall (late gravid). Size at maturity was determined by identifying the smallest males carrying embryos and the smallest females with hydrated, orange eggs observed through the body wall (Vincent 1990, Masonjones 1997). ImageJ (version 1.50d) was used to measure snout, head, torso, tail lengths, and body width in $\mathrm{mm}$ following the procedure of González et al. (2014).

\subsection{Statistical analysis}

Results of statistical tests were considered significant at $\mathrm{p}<0.05$. Environmental variables were assessed to determine differences by zone and between locations from either the north (Control, Caves, Emmas) or south (Quarry, Grouper Cave) ends of the lake. Animal distribution was analyzed by zone and season. Seahorse densities were analyzed by dividing the number of seahorses observed per area in $\mathrm{m}^{2}$ surveyed for each transect. Overall density was calculated both on a landscape level (all transects surveyed for seahorses) and a local scale (only transects where seahorses were observed). Landscape-level densities were analyzed using a generalized linear model (GLM) in R Studio, using an underlying quasi-Poisson distribution comparing animal density across zone (Control, Caves, Emmas, Quarry, Grouper Cave) and season (wet and dry), in addition to location (north and south) and season, because the variable could not 
be transformed to normality due to 18 transects with zero seahorses $(n=118$ total transects). Sum of squares model selected in R was Type III, using the 'car' library.

Local population density (adults and juveniles on non-zero transects) was not normally distributed, and standard data transformations did not achieve normality. Data were analyzed using a nested GLM in R Studio, using an underlying quasi-Poisson distribution comparing local density across location (north and south) and season. Adult density (calculated as the number of sexually mature adults observed on a transect divided by the area sampled [in $\mathrm{m}^{2}$ ]; $\mathrm{n}=100$ transects) was also not normally distributed; variables were square-root transformed and achieved normality, with equal variances displayed in the transformed variable for zone and season. A 2-way ANOVA was performed with zone and season as factors using a Student's $t$-test to determine post hoc differences between groups. Zones were collapsed to north and south locations to investigate patterns of both adult and overall population density on a gross spatial scale along apparent physically divergent habitat lines.

Sex ratio was investigated by zone and season, calculated as the ratio of males to total adult animals seen at that transect. Sex ratio was not normally distributed and had unequal variances across all grouping variables. As a result, a series of Wilcoxon tests were performed with appropriate Holm-Bonferroni sequential corrections (Holm 1979). In addition, deviation from an equal sex ratio was investigated using a series of Wilcoxon signed-ranks tests, testing each for a deviation from a mean sex ratio of 0.5 . The frequency of male reproduction was calculated as the ratio of gravid males to all males observed in the population. Contingency table analyses were conducted to identify potential associations between zone/location/season and the distribution of animals by sex (juvenile, female, male), reproductive category (juveniles, females without/with hydrated eggs, males without/with early embryos/with late embryos), and male reproductive status (not gravid/gravid).

Total body length was not normally distributed, and thus differences were investigated with a nested GLM in R Studio, using an underlying quasi-Poisson distribution comparing animal density across zone (Control, Caves, Emmas, Quarry, Grouper Cave) and season (wet and dry), in addition to location (north and south) and season, using sum of squares model 4 (type III) selected in R. Female and male body lengths were $\log _{10}$ transformed to achieve normality. Variances were equal for log-transformed body lengths across zone and season. Body dimension variables were analyzed using discriminant analysis comparing the snout length, head length, trunk length, and body width (measurements described in González et al. 2014) between males and females, to determine the amount of sexual dimorphism in this species. Morphological variables were analyzed by sex for equal variances using Bartlett's test (all $\mathrm{p}>$ 0.05), to verify the assumption of homogeneity of variance-covariance matrices.

Morphological variables analyzed in Rose et al. (2016) with an independent sample of 90 seahorses from the Caves site only were explored with the larger data set of animals in the present study to determine if the species-specific trends identified previously were supported with the larger data set. Animals were measured using the same techniques as outlined in Rose et al. (2016), and were statistically compared to the morphological measurements provided for Hippocampus reidi (Brazil population, $\mathrm{n}=$ 23), H. erectus (Tampa Bay, eastern United States, $\mathrm{n}=42$ ), and initial Sweetings Pond $H$. erectus samples used previously $(\mathrm{n}=90)$. Individuals were excluded from comparison if they were smaller than the size at maturity for males and females, determined using published age at maturity data for the species or populations involved. For $H$. reidi, a Brazil population of animals was used to determine differences, and animals > $90.2 \mathrm{~mm}$ were considered to be adults, calculated from sites with more than 10 seahorses (see Table 2), from the height of smallest males with a pouch (Rosa et al. 2007, Mai \& Velasco 2012). For oceanic $H$. erectus, Gulf of Mexico/Tampa Bay adult animals were $>90 \mathrm{~mm}$ (Dunham 2010). For Sweetings Pond $H$. erectus, adult females were > $61 \mathrm{~mm}$ and males > $65 \mathrm{~mm}$ (present study). Significant factors from Rose et al. (2016) were analyzed using discriminant analysis comparing the head length, trunk length, tail length, and body width with discriminant analysis across populations (with variables analyzed for equal variances using Bartlett's test, all $\mathrm{p}>0.05$ ). In addition, the ratio of trunk length to tail length and head length to trunk length was compared across populations, to determine whether Sweetings Pond animals have significantly larger heads than these other seahorse populations (a ratio closer to 1 would indicate a longer head relative to the torso). Because of violations in either normality or equal variances, Kruskal-Wallis tests followed by Wilcoxon multiple comparisons were performed to compare body ratios. All statistics, unless otherwise indicated, were performed in JMP Pro v.11.2, with the assumption of normality tested using ShapiroWilk tests and equal variances with Levene's tests. 


\section{RESULTS}

\subsection{Environmental patterns of Sweetings Pond}

Water temperatures varied predictably with season, and also showed significant variation across zone during the dry season (2-way ANOVA, $F_{9,100}=$ $32.90, \mathrm{p}<0.0001$; season by zone, $F_{4,100}=15.29$, $\mathrm{p}<$ 0.0001 ; Tables $1 \& 2$ ). Surface turbidity differed overall, but only significantly by lake zone (2-way ANOVA, $F_{9,100}=3.86, \mathrm{p}<0.001$ ). Midwater turbidity varied significantly by zone and season, with significant interaction effects (2-way ANOVA, $F_{9,70}=4.22$, $\mathrm{p}<0.001$; season by zone, $\left.F_{4,70}=4.55, \mathrm{p}=0.002\right)$. Salinity also varied significantly across the watershed (2-way ANOVA, $F_{9,100}=14.81, \mathrm{p}<0.0001$ ), by zone, season, and with significant interaction effects $\left(F_{4,100}=30.59, \mathrm{p}<0.001\right)$. Overall, salinity was higher in the south end of the lake compared to the north, and predictably higher in the dry season. In addition, $\mathrm{pH}$ was significantly higher in southern sites compared to the north (2-way ANOVA, $F_{9,95}=8.14, \mathrm{p}<$ $0.0001)$, but with no variation seasonally. Nitrate and nitrite were zero across season and zone, but phosphate was slightly but not significantly higher in the dry season (Wilcoxon, $\chi_{95}^{2}=2.717, \mathrm{p}=0.099$ ).

\subsection{Seahorse density patterns}

Overall landscape-level seahorse density was $0.142 \pm 0.013$ ind. $\mathrm{m}^{-2}$ across 118 transects. In total, 18 transects surveyed had no apparent seahorses, and thus the non-zero local transect density was $0.185 \pm$ 0.0146 ind. $\mathrm{m}^{-2}$, with maximum density observed at 0.66 ind. $\mathrm{m}^{-2}$. Landscape-level density differed sig-

Table 1. Mean (SE) environmental variables of Sweetings Pond (Eleuthera, The Bahamas) monitored between March 2014 and March 2016, with sample sizes indicated in column headings

\begin{tabular}{|lcccc|}
\hline \multirow{2}{*}{$\begin{array}{l}\text { Environmental } \\
\text { variable }\end{array}$} & \multicolumn{2}{c}{ North location } & \multicolumn{2}{c|}{ South location } \\
& Dry $(39)$ & Wet $(48)$ & Dry $(15)$ & Wet (19) \\
\hline Salinity (ppt) & $36.6(0.259)$ & $35.5(0.182)$ & $38.8(0.354)$ & $36.6(0.370)$ \\
Surface temp $\left({ }^{\circ} \mathrm{C}\right)$ & $24.1(0.130)$ & $30.2(0.169)$ & $21.9(0.459)$ & $30.8(0.071)$ \\
Air temp $\left({ }^{\circ} \mathrm{C}\right)$ & $27.4(0.526)$ & $30.4(0.360)$ & $24.2(0.578)$ & $30.1(0.248)$ \\
pH & $8.1(0.01)$ & $8.02(0.023)$ & $8.2(0.027)$ & $8.1(0.016)$ \\
Surf. turbidity (NTU) & $1.4(0.353)$ & $2.0(0.253)$ & $1.9(0.297)$ & $1.8(0.100)$ \\
MW turbidity (NTU) & $0.966(0.089)$ & $1.6(0.110)$ & $1.2(0.230)$ & $1.6(0.160)$ \\
Nitrite (ppm) & 0 & $0.042(0.020)$ & 0 & 0 \\
Nitrate (ppm) & $2.9(1.34)$ & $1.7(0.806)$ & $2.7(1.82)$ & 0 \\
Phosphate (ppm) & $0.027(0.011)$ & $0.14(0.014)$ & $0.37(0.052)$ & $0.1(0.027)$ \\
Depth range sampled $(\mathrm{m})$ & $0.6-2.5$ & $0.6-5.8$ & $0.6-2.8$ & $0.6-2.9$ \\
No. seahorses transect ${ }^{-1}$ & $4.0(0.629)$ & $10.0(0.996)$ & $2.2(0.587)$ & $3.84(0.781)$ \\
\hline
\end{tabular}

nificantly by both location (GLM, $\chi^{2}{ }_{1}=4.61, \mathrm{p}=$ 0.032 ) and season $\left(\chi^{2}{ }_{1}=8.76, \mathrm{p}=0.003\right)$, with no interaction effect ( $p=0.87)$ and no effect investigating the relationship with density by zone (Fig. 2). Density was $73.5 \%$ higher overall during the wet season, and $147 \%$ higher in the north compared to the south end of the lake.

Local-level adult seahorse density differed significantly (nested GLM, $\chi^{2}{ }_{1}=173.40, \mathrm{p}<0.0001$ ), both by location and season, but with no significant interaction between the 2 variables (Table 2). Adult densities were $44.1 \%$ lower in the dry season than they were in the wet season. However, when the local density of the entire seahorse population was considered lakewide comparing northern to southern densities, density differed significantly overall (2-way ANOVA, $F_{3,96}=8.14, \mathrm{p}<0.0001$ ), with both seasonal and location differences (Table 2). Overall population densities were $40.1 \%$ lower in the dry season ( $\mathrm{n}=36$ transects) than in the wet season ( $\mathrm{n}=64$ transects), and $48.8 \%$ lower in the south portion of the lake ( $\mathrm{n}=24$ transects) than in the north ( $\mathrm{n}=76$ transects).

\subsection{Seahorse sex ratios}

Sex ratio did not vary across zones, locations, or seasons (Wilcoxon test, all $\mathrm{p}>0.05$ ). However, sex ratio overall was $0.58 \pm 0.03$ ( $\mathrm{n}=94$ transects), which indicated a strongly male-biased population that differed significantly from the expectation of 0.5 , representing an even number of males and females (Wilcoxon test, $\chi_{93}^{2}=2.56, \mathrm{p}=0.009$; Fig. 3). When calculated across all transects excluding immature fish below the breeding size threshold, sex ratio across the watershed was 0.62 ( $n=233$ females and 379 males). When the deviation from an equal distribution by sex was investigated spatially and seasonally, both northern transects and wet season transects significantly differed from an even sex ratio, with both northern transects and wet season transects displaying male-biased sex ratios (Table 2).

\subsection{Seahorse frequency by location and reproductive roles}

No association between location in the lake and gender was detected (Table 2). However, there was a sig- 
Table 2. Summary of main results for survey of the seahorses Hippocampus erectus in Sweetings Pond (Eleuthera, The Bahamas). Global tests are described in the text sections given in parentheses, but specific tests to determine patterns by location and season are indicated. NS: not statistically significant; other values significant at $\mathrm{p}<0.05$

\begin{tabular}{|c|c|c|c|c|}
\hline & $\begin{array}{c}\text { Location } \\
\text { (north vs. south) }\end{array}$ & $\begin{array}{c}\text { Statistical values } \\
\text { location }\end{array}$ & $\begin{array}{c}\text { Season } \\
\text { (wet vs. dry) }\end{array}$ & $\begin{array}{c}\text { Statistical values } \\
\text { season }\end{array}$ \\
\hline \multicolumn{5}{|c|}{ Environmental patterns (Section 3.1) } \\
\hline Water temperature & Higher in north & $\begin{array}{c}F_{4,100}=5.33^{\mathrm{a}} \\
\mathrm{p}<0.001\end{array}$ & Higher in wet & $\begin{array}{c}F_{1,100}=990.43^{\mathrm{a}} \\
\mathrm{p}<0.0001\end{array}$ \\
\hline \multirow[t]{2}{*}{ Turbidity } & Surface higher in south & $\begin{array}{c}F_{4,100}=6.38^{\mathrm{a}} \\
\mathrm{p}<0.0001\end{array}$ & No variation & NS \\
\hline & Midwater higher in south & $\begin{array}{c}F_{4,70}=3.03^{\mathrm{a}} \\
\mathrm{p}=0.023\end{array}$ & Midwater higher in wet & $\begin{array}{c}F_{1,70}=5.58^{\mathrm{a}} \\
\mathrm{p}=0.021\end{array}$ \\
\hline Salinity & Higher in south & $\begin{array}{c}F_{4,100}=19.09^{\mathrm{a}} \\
\mathrm{p}<0.0001\end{array}$ & Higher in dry & $\begin{array}{c}F_{1,100}=14.55^{\mathrm{a}} \\
\mathrm{p}<0.001\end{array}$ \\
\hline $\mathrm{pH}$ & Higher in south & $\begin{array}{c}F_{4,95}=6.88^{\mathrm{a}} \\
\mathrm{p}<0.0001\end{array}$ & No variation & $\mathrm{NS}^{\mathrm{a}}$ \\
\hline \multicolumn{5}{|c|}{ Seahorse density patterns (3.2) } \\
\hline Local adult density & $69 \%$ higher in north & $\begin{array}{l}\chi^{2}{ }_{1}=3.94^{b} \\
p=0.047\end{array}$ & $44 \%$ lower in dry season & $\begin{array}{l}\chi^{2}{ }_{1}=8.50^{b} \\
p=0.004\end{array}$ \\
\hline Local seahorse density & $49 \%$ lower in south & $\begin{array}{c}F_{1,96}=7.91^{\mathrm{a}} \\
\mathrm{p}=0.006\end{array}$ & $40 \%$ lower in dry season & $\begin{array}{c}F_{1,96}=3.99^{\mathrm{a}} \\
\mathrm{p}=0.049\end{array}$ \\
\hline \multicolumn{5}{|l|}{ Sex ratios $(3.3)$} \\
\hline Male-biased sex ratio & $\begin{array}{l}\text { Deviated from equal } \\
\text { sex ratios in north zone }\end{array}$ & $\begin{array}{c}\chi^{2}{ }_{70}=308.50^{c} \\
p=0.042 \\
\alpha=0.05\end{array}$ & $\begin{array}{l}\text { Deviated from equal } \\
\text { sex ratios in wet season }\end{array}$ & $\begin{array}{c}\chi_{62}^{2}=420.00^{c} \\
p<0.001 \\
\alpha=0.025\end{array}$ \\
\hline \multicolumn{5}{|l|}{ Animal frequencies (3.4) } \\
\hline All animals & No variation & $\mathrm{NS}^{\mathrm{d}}$ & Higher in wet & $\begin{array}{c}\chi_{697}^{2}=6.05^{\mathrm{d}} \\
\mathrm{p}=0.049\end{array}$ \\
\hline Juveniles & No variation & $\mathrm{NS}^{\mathrm{d}}$ & No variation & $\mathrm{NS}^{\mathrm{d}}$ \\
\hline Non-gravid males & No variation & $\mathrm{NS}^{\mathrm{d}}$ & Higher in wet season & $\begin{array}{l}\chi_{4}^{2}=37.49^{d} \\
p<0.0001\end{array}$ \\
\hline Gravid males & No variation & $\begin{array}{l}\chi^{2}{ }_{1}=1.23^{\mathrm{d}} \\
\mathrm{p}=0.267\end{array}$ & Higher in dry season & $\begin{array}{l}\chi^{2}{ }_{1}=23.35^{\mathrm{d}} \\
\mathrm{p}<0.0001\end{array}$ \\
\hline \multicolumn{5}{|l|}{ Size differences (3.5) } \\
\hline All animals surveyed & Larger fish in south only in wet & $\begin{array}{c}\chi^{2}{ }_{1}=13.58^{b} \\
p<0.001\end{array}$ & Larger fish in wet & $\begin{array}{c}\chi^{2}{ }_{1}=12.69^{b} \\
p<0.001\end{array}$ \\
\hline Males & Larger fish in south & $\begin{array}{c}F_{1,391}=19.13^{\mathrm{a}} \\
\mathrm{p}<0.0001\end{array}$ & Larger in wet & $\begin{array}{c}F_{1,386}=22.31^{\mathrm{a}} \\
\mathrm{p}<0.0001\end{array}$ \\
\hline Females & No variation & $\mathrm{NS}^{\mathrm{a}}$ & Larger in wet & $\begin{array}{c}F_{1,260}=5.99^{\mathrm{a}} \\
\mathrm{p}=0.015\end{array}$ \\
\hline \multicolumn{5}{|c|}{ a Tested by 2-way ANOVA } \\
\hline \multicolumn{5}{|c|}{ bested generalized linear model } \\
\hline \multicolumn{5}{|c|}{${ }^{c}$ Wilcoxon tests with Bonferroni corrections for multiple tests (Holm 1979) } \\
\hline${ }^{\mathrm{d}}$ Contingency table anc & ysis using likelihood ratio methoc & & & \\
\hline
\end{tabular}

nificant association between season and the frequency of males, females, and juveniles (Fig. 4, Table 2), with higher frequencies overall in the wet season than in the dry season. For juveniles analyzed separately, however, there was no significant difference in the counts observed by transect in the wet season than the dry season (wet $\mathrm{n}=64$, mean $=1.50 \pm 0.26$ transect $^{-1}$; dry $\mathrm{n}=36$, mean $=1.06 \pm 0.35$ transect $^{-1}$, Wilcoxon test, $\chi^{2}{ }_{1}=0.291, \mathrm{p}=0.590$ ). Investigating the finer details of reproduction by season, all groups had similar frequencies between wet and dry seasons ex- cept for non-gravid males, which were more frequent in the wet than the dry season (Table 2). A significant association was detected between the frequency of reproduction in males by zone, with a higher proportion of breeding males observed in Caves than the other zones (contingency table analysis, $\chi^{2}{ }_{1}=13.97, \mathrm{p}$ $=0.007$; Fig. 4). This difference did not translate to a north-south pattern, however, with similar frequencies of breeding males in the north and the south (Table 2). Seasonally, there was a higher proportion of gravid males than non-gravid males observed in the 


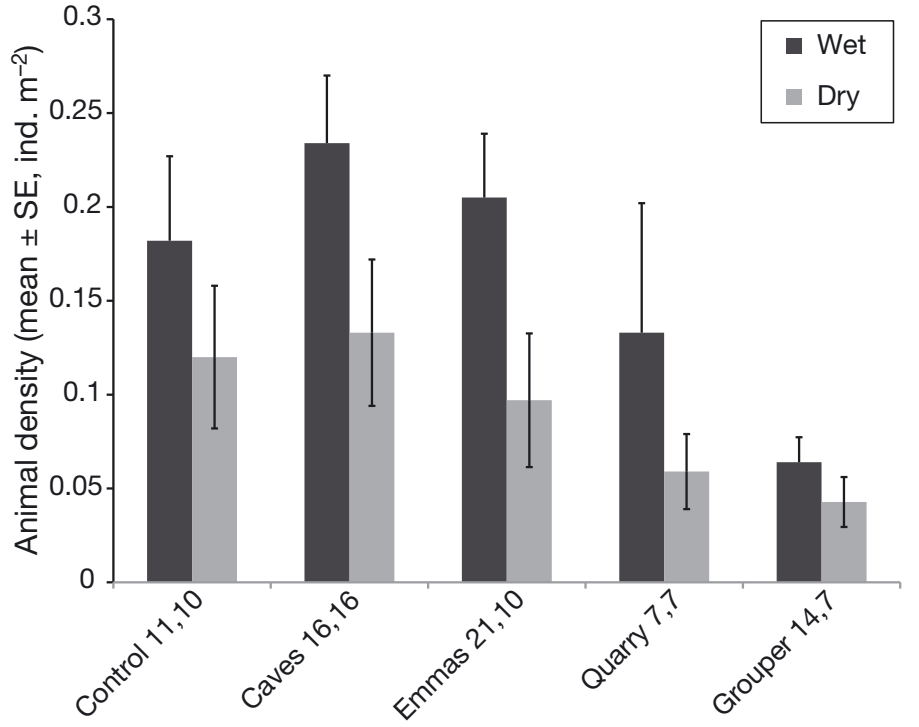

Fig. 2. Overall landscape-level population density of Hippocampus erectus differences organized both spatially and seasonally $(\mathrm{n}=119$ transects; numbers beside zones on $x$-axis show number of transects for wet and dry seasons, respectively). Density provided for all observed animals (males, females, juveniles) as no. of animals $\mathrm{m}^{-2}$ for northern zones (Control, Caves, Emmas) and southern zones (Quarry, Grouper Cave) and by wet (May-October) and dry (November-April) seasons

dry season, with more non-gravid males seen in the wet season.

\subsection{Bahamian seahorse morphometric analyses}

Animals ranged in size from 27.9-152.3 mm (mean $=90.2 \mathrm{~mm}, \mathrm{n}=697$ animals). The smallest size at which females displayed ripe eggs was $61 \mathrm{~mm}$, and for males carrying embryos it was $65 \mathrm{~mm}$ (reproductive maturity; Table 3 ). Body length across the population differed significantly (GLM, $\chi^{2}{ }_{1}=$ 79724.27, p < 0.0001), for both season and location, with an interaction detected between location and season $\left(\chi^{2}{ }_{1}=5.95, p=0.015\right.$; Tables $\left.2 \& 3\right)$. Seasonally, animals were substantially larger $(7.9 \mathrm{~mm})$ during the wet compared to the dry season. Body sizes in the 3 northern sites (Control, Caves, Emmas; global $F_{3,693}=14.86, \mathrm{p}<0.0001$; location: $F_{1,689}=4.09, \mathrm{p}=$ 0.043 ) were $11.3 \mathrm{~mm}$ smaller during the wet season than those from the southern sites (Quarry, Grouper Cave, season: $F_{1,689}=28.99, \mathrm{p}<0.0001$; season $\times$ location: $F_{1,689}=7.29, \mathrm{p}=0.007$ ), with no differences detected in the dry season.

Males and females differed significantly in body length, seasonally and spatially, with no interaction effects (3-way ANOVA, $F_{19,666}=4.38, \mathrm{p}<0.0001$;

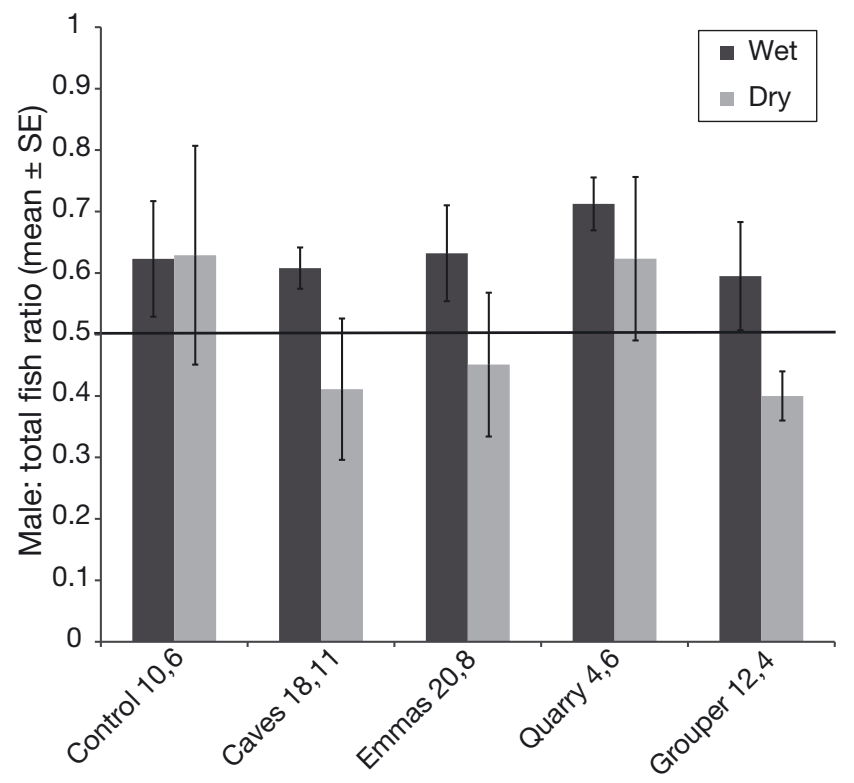

Fig. 3. Variation in Hippocampus erectus population sex ratio (number of males per transect divided by the number of total fish observed on a transect; numbers beside zones on $x$-axis show number of transects included in analysis for wet and dry seasons, respectively) by both zone (northern zones: Control, Caves, Emmas; southern zones: Quarry, Grouper Cave) and season (wet: May-October; dry: November-April)

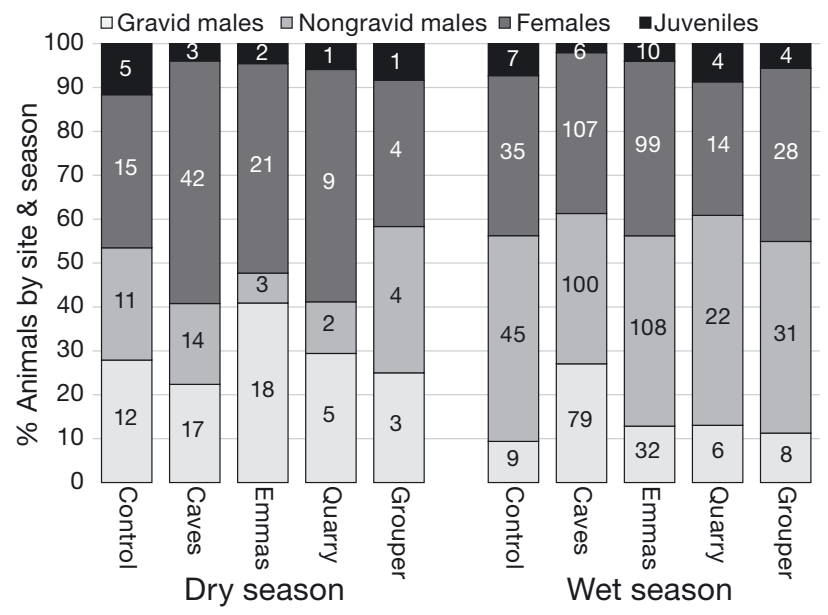

Fig. 4. Frequency of male (gravid and nongravid), female, and juvenile Hippocampus erectus by season (wet: MayOctober; dry: November-April) and zone (northern zones: Control, Caves, Emmas; southern zones: Quarry, Grouper Cave). Numbers in columns indicate numbers of seahorses in each category

Table 3). Males were $4.8 \%$ longer than females, and this was consistently observed across season and zone. Comparing the body dimensions of males and females using a discriminant analysis indicated they differed significantly (Fig. 5 ; Wilks lambda test, $\lambda=$ $\left.0.697, F_{5,559}=48.70, \mathrm{p}<0.0001\right)$ and were non-overlapping, with $76.07 \%$ of animals correctly classified 
Table 3. Sexual differences across Hippocampus erectus from Sweetings Pond (Eleuthera, The Bahamas). Units provided in first column; values are given as means $( \pm$ SE). Data from Tampa Bay are from Dunham (2010); data from the Gulf of Mexico are from Baum et al. (2003)

\begin{tabular}{|c|c|c|c|c|}
\hline \multicolumn{2}{|l|}{ Variable } & Females & \multicolumn{2}{|c|}{ Males } \\
\hline \multicolumn{2}{|c|}{ Sample size (n) } & 270 & \multicolumn{2}{|c|}{396} \\
\hline \multicolumn{5}{|c|}{ Size first reproduction (mm) } \\
\hline \multicolumn{2}{|c|}{ Sweetings Pond } & 61 & \multicolumn{2}{|r|}{65} \\
\hline \multicolumn{2}{|l|}{ Tampa Bay } & 85 & \multicolumn{2}{|c|}{90} \\
\hline \multicolumn{2}{|l|}{ Gulf of Mexico } & 105.3 & \multicolumn{2}{|c|}{105.3} \\
\hline \multicolumn{2}{|c|}{ Body length (mm) } & $89.0(1.21)$ & \multicolumn{2}{|c|}{$93.2(0.80)$} \\
\hline \multicolumn{2}{|c|}{ Range - body length (mm) } & $43.7-151.6$ & \multicolumn{2}{|c|}{$58.9-152.3$} \\
\hline \multicolumn{2}{|c|}{ Snout length (mm) } & $8.54(0.17)$ & \multicolumn{2}{|c|}{$8.45(0.11)$} \\
\hline \multicolumn{2}{|l|}{ Head length (mm) } & $19.6(0.30)$ & \multicolumn{2}{|c|}{$20.2(0.19)$} \\
\hline \multicolumn{2}{|l|}{ Trunk length (mm) } & $30.1(0.42)$ & \multicolumn{2}{|c|}{$30.9(0.29)$} \\
\hline \multicolumn{2}{|l|}{ Tail length (mm) } & $39.3(0.52)$ & \multicolumn{2}{|c|}{$42.0(0.37)$} \\
\hline \multicolumn{2}{|l|}{ Body width (mm) } & $11.7(0.17)$ & \multicolumn{2}{|c|}{$13.3(0.12)$} \\
\hline Pouch length (mm) & & - & \multirow{2}{*}{\multicolumn{2}{|c|}{$\begin{array}{l}11.1(0.18) \\
6.27(0.11)\end{array}$}} \\
\hline \multicolumn{2}{|l|}{ Pouch width (mm) } & - & & \\
\hline & Wet & Dry & Wet & Dry \\
\hline Sample size (n) & 208 & 62 & 323 & 73 \\
\hline \multirow[t]{2}{*}{ Body length (mm) } & $90.1(1.35)$ & $85.4(2.67)$ & $94.5(0.86)$ & $87.1(1.95)$ \\
\hline & No eggs & Visible eggs & Non-gravid & Gravid \\
\hline Sample size (n) & 139 & 90 & 261 & 135 \\
\hline Body length (mm) & $90.3(1.55)$ & $96.3(2.00)$ & $92.2(1.06)$ & $95.0(1.12)$ \\
\hline
\end{tabular}

Female body size was right-skewed, with females ranging from 43.7 to $151.6 \mathrm{~mm}$ (mean $=89.02 \pm 1.21 \mathrm{~mm})$. Female body size differed significantly across variables (2-way ANOVA on logtransformed body length, $F_{9,260}=2.64$, $\mathrm{p}=0.006$; Table 3), with larger females observed in the wet season but no size difference observed by zone and no interaction observed between zone and season. Females with hydrated eggs visible through the body wall were significantly larger than females without visible eggs and juvenile females (1-way ANOVA, $F_{2,266}=44.92, p<0.0001$; Student's $t$-test with multiple comparisons, all $\mathrm{p} \leq 0.01$ ).

Male body size was also right-skewed, with males ranging from 58.9 to $152.3 \mathrm{~mm}$ (mean $=94.2 \pm 0.799 \mathrm{~mm}$ ). Male body sizes differed across zone and season (2-way ANOVA on log-transformed body lengths, $F_{9,386}=5.26, \mathrm{p}<$ 0.0001; Table 3), with significantly larger males in the wet season and a significant interaction effect $\left(F_{4,386}=2.78, \mathrm{p}=0.027\right)$. Gravid males were $2.93 \%$ larger than

by sex. This difference appears to be driven by differences in tail length and body width, because those were the only means that varied between males and females.

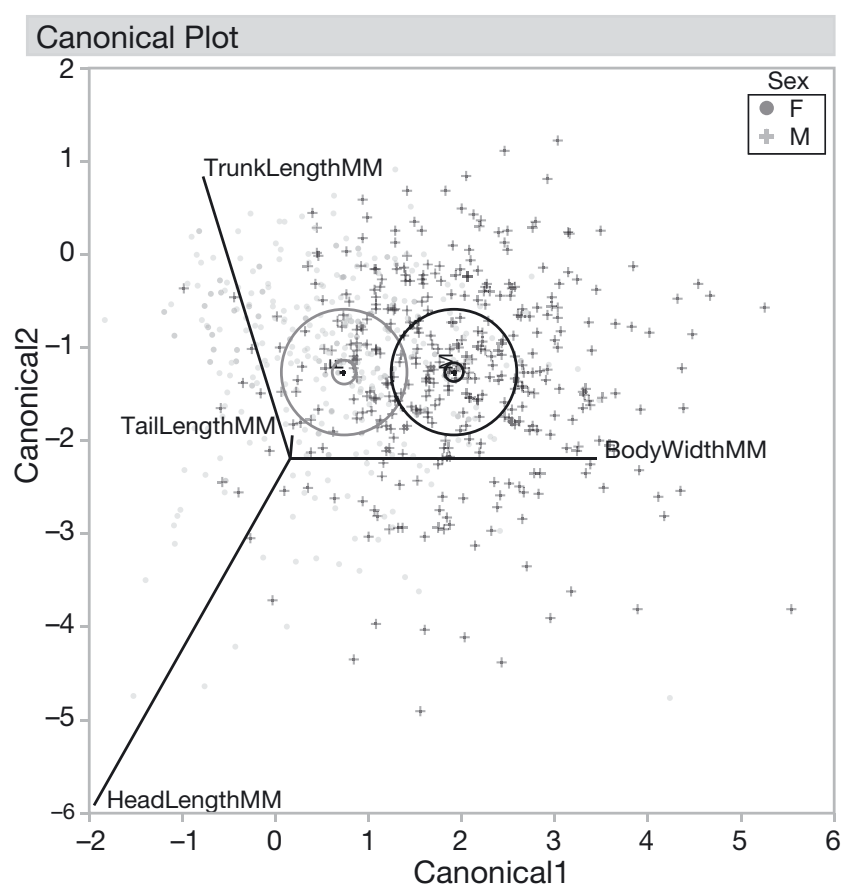

non-gravid males $\left(F_{1,391}=15.37, \mathrm{p}=0.0001\right)$, with males overall $7.8 \%$ larger in the wet than the dry season, but $8.5 \%$ smaller in the northern sites than the south (north: $92.04 \pm 0.850 \mathrm{~mm}, \mathrm{n}=339$; south: $99.89 \pm 2.078 \mathrm{~mm}, \mathrm{n}=57$ ).

\subsection{Population- and species-level morphometric analyses}

A discriminant analysis indicated that mean centroids (95\% confidence region) for the 4 populations/species were significantly different and nonoverlapping, with $77 \%$ of animals correctly classified

Fig. 5. Canonical plot for the linear discriminant analysis comparing the morphological measurements of Hippocampus erectus (head length, $L_{\mathrm{H}}$, body width, $L_{\mathrm{BW}}$, trunk length, $L_{\mathrm{Tr}}$, tail length, $L_{\mathrm{Ta}}$ ) across sexes (adult females above $61 \mathrm{~mm}$ and adult males above $65 \mathrm{~mm}$ ). Inner ellipses indicate $95 \%$ confidence level for each multivariate mean and outer ellipses indicate $50 \%$ contours for the region of space between the first 2 canonical variables, containing $50 \%$ of the observations. Labeled rays indicate the strength and direction of the loading of covariates on the canonical variables, but for legibility, these rays have been moved from the grand mean of the canonical variables 
(Wilks test, $\lambda=0.28, F_{15,1905}=74.38, \mathrm{p}<0.0001$; Table 4). When comparing trunk to tail ratios, the Sweetings Pond seahorses had more evenly proportioned trunk to tail ratios (0.78 Caves location [Rose et al. 2016] and 0.76 [present study] for all locations), unlike the other Hippocampus erectus (0.66) and $H$. reidi (0.59) samples, which were much more tailbiased (Tables $2 \& 4$; Kruskal-Wallis, $\chi^{2}{ }_{3}=107.02, \mathrm{p}<$ 0.0001 , all groups significantly different from one another, Wilcoxon test, all $\mathrm{p}<0.005$ ). Head to trunk length ratios significantly differed between populations as well (Kruskal-Wallis, $\chi^{2}{ }_{3}=84.04, \mathrm{p}<0.0001$ ); however, ocean populations of $H$. erectus and $H$. reidi did not differ from each other (Wilcoxon test, $\mathrm{p}=$ 0.58; present study Sweetings Pond vs. Rose et al. (2016) Sweetings Pond, $\mathrm{p}=0.017$; all other comparisons $\mathrm{p}<0.005)$. As a result of the differentiation in the various sites across the lake, both trunk to tail and head to trunk ratios differed significantly between the Sweetings Pond seahorses from the present study and the previous samples which had been collected solely from the Caves site. Because of differences that were detected in morphological traits and ratios by sex (Fig. 5) and differences in the number of males and females by zone, with only one zone represented in the previous study, the presence of non-overlapping samples between original Sweetings Pond samples and the present study was to be expected.

\section{DISCUSSION}

This study found that the Sweetings Pond Hippocampus erectus population is both robust and dynamic compared to worldwide seahorse populations (mean worldwide natural density, $0.06 \pm$ 0.021 animals $\mathrm{m}^{-2} ; \mathrm{H}$. Masonjones \& E. Rose unpubl. data), known $H$. erectus populations in the Gulf of Mexico (Baum et al. 2003, Masonjones et al. 2010, Stallings et al. 2014), and seahorse abundance estimates from Aronson (1985) in Sweetings Pond in
1982. In this latter study, which focused on the region of the lake near our Emmas site, seahorses were described as 'rare', seen less than once per dive. In our estimates in the region, seahorses would now be classified in Aronson's scale as 'abundant', with 2 of the 4 highest transect seahorse densities observed in the lake $\left(0.53,0.52\right.$ animals $\mathrm{m}^{-2}$, compared with the max. density observed, 0.67 animals $\mathrm{m}^{-2}$, Caves site). This change across time is most likely explained by the fact that in the early 1980s, Sweetings Pond was surrounded by cattle farming, with evidence of eutrophication in the water column and extensive die-offs of benthic algae and oyster reef structures, creating a void in critical habitat for seahorses (Young 1966, Aronson 1985, Aylesworth et al. 2015). Viable habitat coverage has since recovered in the lake, potentially contributing to the increase in seahorses observed in the present study.

Adult $H$. erectus densities were high across the lake and in a range of habitats, in spite of the significant spatial heterogeneity in habitats across the zones of the lake (J. Curtis-Quick \& H. Masonjones et al. unpubl. data). This indicates that adult seahorses at least are using a range of habitats, which will be investigated further in ongoing habitat preference studies. When the entire population of seahorses was assessed, however, the population density was found to be $48 \%$ lower in the south end of the lake. The addition of juveniles to the population totals indicates a higher concentration of smaller animals, and thus evidence of more reproduction in the northern end of the lake, consistent with the higher number of gravid males in that region. Dry season densities were smaller than those observed in the wet season for both adults and the entire population considered together; thus there is support for a strong seasonal component to seahorse population dynamics. Although overall body sizes were larger in the summer, when analyzed seasonally and spatially, body sizes for the north end of the pond were observed to be significantly smaller during the wet season, also supporting the hypothesis that there is more reproduc-

Table 4. Morphological comparisons, including means and ranges (in parentheses), for ratios of seahorse Hippocampus spp. head length $\left(L_{\mathrm{H}}\right)$, trunk length $\left(L_{\mathrm{Tr}}\right)$, and tail length $\left(L_{\mathrm{Ta}}\right)$ for adult seahorses in the present study $(\mathrm{n}=551)$, original Caves site Sweetings Pond seahorses (Rose et al. 2016, $\mathrm{n}=90$ ), Florida Gulf Coast H. erectus ( $\mathrm{n}=36$ ), and H. reidi from Brazil (Ho et al. $2015, \mathrm{n}=22$ )

\begin{tabular}{|lcccc|}
\hline Trait & $\begin{array}{c}\text { Sweetings Pond } \\
\text { H. erectus }\end{array}$ & $\begin{array}{c}\text { Sweetings Pond } \\
\text { H. erectus }\end{array}$ & FL Gulf Coast (US) & H. erectus \\
& $0.66(0.53-0.80)$ & $0.64(0.56-0.75)$ & $0.58(0.52-0.67)$ & Brazil \\
$L_{\mathrm{H}} / L_{\mathrm{Tr}}$ & $0.76(0.55-1.09)$ & $0.78(0.65-0.99)$ & $0.66(0.54-0.76)$ & $0.58(0.48-0.72)$ \\
$L_{\mathrm{Tr}} / L_{\mathrm{Ta}}$ & & $0.59(0.48-0.75)$ \\
\hline
\end{tabular}


tion occurring in (or more offspring recruiting to) the north end of the lake. Larger sizes overall during the summer months could also provide evidence for a seasonal migration of adults to deeper water, as seen in other syngnathid species (Lazzari \& Able 1990, Monteiro et al. 2006, Boehm et al. 2015). Recent surveys deeper than $5 \mathrm{~m}$ found a lower density of adult animals and sparse vegetation at deeper depths, and as a result, our future studies will include deeper depths in seasonal surveys to determine if larger adults are moving deeper during colder months.

Studies of seahorses globally indicated that populations are substantially lower in density than observed in the present study ( $\mathrm{H}$. Masonjones \& E. Rose unpubl. data). Although maximum densities reported are occasionally higher than those observed for $H$. erectus in Sweetings Pond, such as known high-density populations of $H$. guttulatus in the Algarve lagoon, Portugal (Curtis \& Vincent 2005, 2006, Correia et al. 2015, 2018), mean densities across the lake are at least an order of magnitude higher than all other seahorse populations described to date (H. Masonjones \& E. Rose unpubl. data). In addition, some studies present seahorse densities for non-zero samples only, reporting only local densities rather than also including landscape densities that include transects with zeros (summarized in Foster \& Vincent 2004). Focal studies also typically report higher densities of seahorses compared to studies using random transects or seining approaches, because focal studies are typically conducted in areas previously identified to have high local seahorse densities (H. Masonjones \& E. Rose unpubl. data). Seahorse density in other populations has also been reduced by habitat destruction, overharvesting for traditional medicines, non-selective fishing gear, higher natural predator densities, and a multitude of other factors (Foster \& Vincent 2004, Vincent et al. 2011, Harasti et al. 2014a).

An additional highly unusual feature of the present population of $H$. erectus was the consistent observation of male-biased sex ratios over time and space (0.58), with no differences observed by zone, location, or season. Male-biased populations have rarely been observed in other species ( $H$. capensis, Bell et al. 2003; H. whitei, Clynick 2008), which consistently demonstrate even to female-biased sex ratios (H. Masonjones \& E. Rose unpubl. data). This pattern was strongest for northern populations during the wet (summer) season, with an observed sex ratio of 0.62 (0.39). This finding is consistent with the observation of a smaller fraction of males carrying embryos in the north during the summer. If males are in excess in this population, then relatively fewer females are available for mating, thus leaving some males potentially without mates in this hypothetically monogamous species (Jones \& Avise 2001, Wilson \& Martin-Smith 2007, Woodall et al. 2011, Rose et al. 2014). With males in excess, there may be stronger sexual selection driving the sexual size dimorphism observed in the population, a process observed in other species (Jones et al. 2000, Sefc 2008, Flanagan et al. 2014, McCullough et al. 2018). Male Sweetings Pond seahorses overall have been observed to be $4.8 \%$ larger than females, with this size difference strongest between gravid and non-gravid males (3\% size difference). This may be driven by the longer tails of males, a sexually dimorphic trait observed in $H$. erectus and other seahorse species (Bell et al. 2003, Anderson 2012). It is possible that there is higher natural selection on females (higher mortality), but since food is not limiting in this system $(\mathrm{H}$. Masonjones \& R. Waggett unpubl. data), it is unclear what factors may be responsible. Female seahorses carrying hydrated eggs were larger than females without this visual cue, and it is possible that egg production is a limiting factor for females, causing differential mortality between the sexes, and consequently males being larger simply because they are older.

Finally, this population strongly deviated from the size and shape of other populations of $H$. erectus studied. They appear to mature at roughly $20-45 \mathrm{~mm}$ smaller than other $H$. erectus populations throughout the species' range (Table 3) (Silveira \& Silva 2016) and achieve smaller terminal sizes overall $(152 \mathrm{~mm}$, present study; $161 \mathrm{~mm}$, Dunham 2010; $202 \mathrm{~mm}$, Baum et al. 2003). Facultative dwarfism among Octopus brierus was observed in the pond; a paired study of octopus from the pond raised in the laboratory indicated that animals raised in the pond were significantly smaller, and octopus from the pond were generally smaller than those observed elsewhere in the Caribbean (Aronson 1985). Maturing at a smaller size with smaller overall body sizes can be associated with intense predation or overexploitation (de Roos et al. 2006), but higher temperatures, crowding, and resource limitation can also contribute (Aronson 1985). Bergmann's Rule suggests that decreasing latitude and thus increasing temperature is associated with smaller overall body sizes (Fisher et al. 2010). Sweetings Pond is a shallow body of water, and therefore will experience a higher range of temperatures in comparison to the surrounding ocean.

Summer monitoring of ocean and Sweetings Pond water temperatures in 2016 for a separate project indicated that lake temperatures were $1^{\circ} \mathrm{C}$ higher at 
the north end and $1.5^{\circ} \mathrm{C}$ higher at the south than immediately offshore, and all were substantially higher than Gulf of Mexico water temperatures during the same period, so temperature could play a strong role in the evolution of smaller body size in this lake population (H. Masonjones unpubl. data). Bergmann's Rule has been confirmed for genera in the same family as seahorses, although not in seahorses themselves, hypothesized to be because of differences in mating systems between multiplemating pipefishes and monogamous seahorses (Wilson 2009).

Smaller body size in this lake population cannot be completely considered dwarfism or nanism because seahorses' heads appear to have remained large, with the allometric relationship shifted between the head, body and tail. Across island and insular population examples, dwarfism is associated with a range of selective pressures, including low $\mathrm{pH}$, high predator densities, the presence of larger competitors, and low food availability (Lomolino 2005, Herczeg et al. 2009, MacColl et al. 2013, Rollins 2017). This system displayed low predator densities in the early 1980s, but with the consistent addition of young grouper and snapper by the local fishing community since that time, and limited harvesting of crabs, it is possible that predation shifted body sizes downward. In addition, it is unclear whether the octopus in the system are predators on seahorses, as they are in other systems (Harasti et al. 2014a). The decoupling of head size from overall body size could indicate stabilizing selection on head size, possibly due to mating preferences or prey size availability. In syngnathid fishes, fecundity in females and brooding capacity in males scales with body size, associated with preferences by males and females for larger mates, which translates consistently into size-assortative mating patterns (Jones et al. 2003, Kvarnemo et al. 2007, Naud et al. 2009). Preference for larger mates would theoretically lead to larger body sizes overall (Rosenqvist \& Berglund 2011, Bahr et al. 2012), not observed in this population. However, opposing natural selection for smaller body size and sexual selection for larger body size could favor the decoupling of head and overall body sizes, leading to the change in allometry in this population from other known $H$. erectus populations. A more probable cause for the shift in head allometry is prey size and availability, correlated with changes in head shape and feeding apparatus changes across insular populations from a range of species (Herrel et al. 2008, Lillywhite \& McCleary 2008, Lamichhaney et al. 2018). Longer snouts in seahorses, translating to longer heads, is associated with reduced time to reach distant prey, balanced by decreasing the flow velocity through the longer snout (Roos et al. 2010, 2011, Manning et al. 2019). Although currently unknown, this unusual lake ecosystem may have a range of prey that favors longer snouts, stabilizing head size. Future studies will investigate these patterns.

The results from this study show that the seahorses inhabiting this isolated saltwater lake are distributed at a density consistently higher than most known seahorse species observed. Although they genetically cluster with $H$. erectus, these animals have significantly shorter tails and longer heads than other populations of the species (Rose et al. 2016, present study), and both mature 22-40\% smaller than Tampa Bay and larger Gulf of Mexico populations of $H$. erectus (Baum et al. 2003, Dunham 2010, Silveira \& Silva 2016), and have smaller terminal body sizes. Given these differences, their geographic isolation, and their small range size, they should be considered a separate management unit for the purposes of conservation and protection. Future research will focus on determining their potential status as a separate subspecies using molecular techniques to investigate the genetic mechanisms underlying local adaptation, potential patterns of allele fixation, and will test for a depletion of heterozygosity in this isolated population. From a genetic perspective, this collection of seahorses represents a unique opportunity to study a population that has a large amount of phenotypic variation yet has no gene flow from outside the lake. In a previous study using RADseq genomic techniques to determine population structure of the lined seahorse, Boehm et al. (2015) found 3 distinct subpopulations that were genetically divergent and isolated by distance across the range of $H$. erectus. Other syngnathid populations have shown substantial population structuring at low spatial scales, with geographic isolation leading to genetic differences between populations (Boehm et al. 2013, 2015, Fedrizzi et al. 2015, Mkare et al. 2017), so it is highly possible that, given the strong evidence of geographic isolation in this population, they will have accrued genetic differentiation.

Sweetings Pond is a highly unique site of global importance due to the high density of seahorses inhabiting the lake. Potential risks exist for this isolated population, including agriculture on the pond edge expanding at a rate of more than $2{\text { ha } \mathrm{yr}^{-1}}$ (H. Masonjones unpubl. data), increasing tourist pressure, and seahorse harvests, making rapid action critical to ensure their persistence into the future. Any threats that lead to the degradation of benthic habitat or water 
quality in the lake will have serious implications for this isolated population, as shown in other seahorse species around the world (H. reidi, Aylesworth et al. 2015; H. whitei, Harasti 2016; H. guttulatus, Caldwell \& Vincent 2012). The Sweetings Pond seahorse population provides the opportunity to study the evolution and conservation biology of a seahorse population shortly after the colonization of a novel, isolated habitat. We advocate for its immediate protection and encourage future conservation governance to consider the findings of this paper to guide the management and, in particular, tourism of the lake. For example, the timings and locations that visitors could access should be guided by the seasonal and spatial use of gravid males to avoid negatively impacting reproductive success of the seahorses. This population is unique because it is not threatened by trawling pressures and can serve as a control population for studying growth, aging, and reproductive dynamics to compare with the behavior of populations with more depressed numbers due to anthropogenic change. Seahorses are declining globally (Vincent et al. 2011, Harasti 2016, Lourie et al. 2016), and The Bahamas has a rare opportunity to protect a large number of seahorses in a relatively small geographic area, thus making an important contribution to the conservation of this vulnerable genus.

Acknowledgements. This study was supported by a grant awarded to H.M. from The University of Tampa Dana Foundation, University of Tampa Sabbatical Program, Delo Research Professor Foundation, UT Board of Fellows Grant Program, The UT Biology Department, an Environmental Protection Agency STAR fellowship (FP917497) awarded to E.R., The Bahamas National Trust to support Peter Graham, and general support from J. Yaskin and P. Hollinsed-Hartman for the project. In addition, we especially thank The Leon Levy Native Plant Preserve, Bahamas National Trust for logistical, equipment and staff support and Cape Eleuthera Institute and the Island School for support for research equipment, tanks, and fills. The authors thank Ethan Freid, Mark Daniels, Peter Graham, David Mahlmann, Bridgette Froeschke, Sawyer Masonjones, Kellerin Masonjones, Alana Boyles, Katie Duval, Christina Darville, Liz Pendergrass, The 2014, 2015, and 2016 Reef Ecology teams, Rob Drummond, Logan Zeinert, Alanna Waldman, Pauline Narvaez, Cara Thompson, Drew Hitchner, Lili Wagner, Alexio Brown and many other people for their assistance in the field. Thanks to Michael Masonjones for assistance with GIS analysis and mapping.

\section{LITERATURE CITED}

Anderson PA (2012) Sexual dimorphism in morphometry and allometry of the adult lined seahorse, Hippocampus erectus. Copeia 2012:389-393

Aronson RB (1985) Ecological release in a Bahamian salt water lake: Octopus briareus (Cephalopoda) and Ophiothrix oerstedii (Ophiuroidea). PhD dissertation, Harvard University, Cambridge, MA

Aronson RB, Harms CA (1985) Ophiuroids in a Bahamian saltwater lake: the ecology of a paleozoic-like community. Ecology 66:1472-1483

* Aylesworth LA, Xavier JH, Oliveira TPR, Tenorio GD, Diniz AF, Rosa IL (2015) Regional-scale patterns of habitat preference for the seahorse Hippocampus reidi in the tropical estuarine environment. Aquat Ecol 49:499-512

Bahr A, Sommer S, Mattle B, Wilson AB (2012) Mutual mate choice in the potbellied seahorse (Hippocampus abdominalis). Behav Ecol 23:869-878

Baum JK, Vincent ACJ (2005) Magnitude and inferred impacts of the seahorse trade in Latin America. Environ Conserv 32:305-319

Baum JK, Meeuwig JJ, Vincent ACJ (2003) Bycatch of lined seahorses (Hippocampus erectus) in a Gulf of Mexico shrimp trawl fishery. Fish Bull 101:721-731

* Becking LE, Erpenbeck D, Peijnenburg KTCA, de Voogd NJ (2013) Phylogeography of the sponge Suberites diversicolor in Indonesia: insights into the evolution of marine lake populations. PLOS ONE 8:e75996

Bell EM, Lockyear JF, McPherson JM, Dale Marsden A, Vincent ACJ (2003) First field studies of an endangered South African seahorse, Hippocampus capensis. Environ Biol Fishes 67:35-46

Boehm JT, Woodall L, Teske PR, Lourie SA, Baldwin C, Waldman J, Hickerson M (2013) Marine dispersal and barriers drive Atlantic seahorse diversification. J Biogeogr 40:1839-1849

* Boehm JT, Waldman J, Robinson JD, Hickerson MJ (2015) Population genomics reveals seahorses (Hippocampus erectus) of the western mid-Atlantic coast to be residents rather than vagrants. PLOS ONE 10:e0116219

Caldwell IR, Vincent ACJ (2012) Revisiting two sympatric European seahorse species: apparent decline in the absence of exploitation. Aquat Conserv 22:427-435

Clynick BG (2008) Harbour swimming nets: a novel habitat for seahorses. Aquat Conserv 18:483-492

Correia M, Caldwell IR, Koldewey HJ, Andrade JP, Palma J (2015) Seahorse (Hippocampinae) population fluctuations in the Ria Formosa Lagoon, south Portugal. J Fish Biol 87:679-690

* Correia M, Koldewey HJ, Andrade JP, Esteves E, Palma J (2018) Identifying key environmental variables of two seahorse species (Hippocampus guttulatus and Hippocampus hippocampus) in the Ria Formosa lagoon, South Portugal. Environ Biol Fishes 101:1357-1367

* Curtis J, Vincent A (2005) Distribution of sympatric seahorse species along a gradient of habitat complexity in a seagrass-dominated community. Mar Ecol Prog Ser 291:81-91

* Curtis JMR, Vincent ACJ (2006) Life history of an unusual marine fish: survival, growth and movement patterns of Hippocampus guttulatus Cuvier 1829. J Fish Biol 68: 707-733

Dawson MN (2016) Island and island-like marine environments: marine island biogeography. Glob Ecol Biogeogr 25:831-846

* de Roos AM, Boukal DS, Persson L (2006) Evolutionary regime shifts in age and size at maturation of exploited fish stocks. Proc Biol Sci 273:1873-1880

Dunham NM (2010) The life history and energy budget of Hippocampus erectus in Tampa Bay, Florida. MSc thesis, University of South Florida, Tampa, FL 
Fedrizzi N, Stiassny MLJ, Boehm JT, Dougherty ER, Amato G, Mendez M (2015) Population genetic structure of the dwarf seahorse (Hippocampus zosterae) in Florida. PLOS ONE 10:e0132308

Fisher JAD, Frank KT, Leggett WC (2010) Global variation in marine fish body size and its role in biodiversity-ecosystem functioning. Mar Ecol Prog Ser 405:1-13

Flanagan SP, Johnson JB, Rose E, Jones AG (2014) Sexual selection on female ornaments in the sex-role-reversed Gulf pipefish (Syngnathus scovelli). J Evol Biol 27: 2457-2467

Foster SJ, Vincent ACJ (2004) Life history and ecology of seahorses: implications for conservation and management. J Fish Biol 65:1-61

*González R, Dinghi P, Corio C, Medina A, Maggioni M, Storero L, Gosztonyi A (2014) Genetic evidence and new morphometric data as essential tools to identify the Patagonian seahorse Hippocampus patagonicus (Pisces, Syngnathidae). J Fish Biol 84:459-474

Gould GC, MacFadden BJ (2004) Chapter 17: gigantism, dwarfism, and Cope's Rule: 'Nothing in evolution makes sense without a phylogeny. Bull Am Mus Nat Hist 285: 219-237

Gristina M, Cardone F, Carlucci R, Castellano L (2015) Abundance, distribution and habitat preference of Hippocampus guttulatus and Hippocampus hippocampus in a semi-enclosed central Mediterranean marine area. Mar Rundsch 36:57-66

*Han SY, Rho S, Noh GE, Kim JK (2018) Interspecific hybridization in seahorses: artificially produced hybrid offspring of Hippocampus kuda and Hippocampus reidi. Fish Aquat Sci 21:11

*Harasti D (2016) Declining seahorse populations linked to loss of essential marine habitats. Mar Ecol Prog Ser 546: 173-181

Harasti D, Martin-Smith K, Gladstone W (2014a) Does a notake marine protected area benefit seahorses? PLOS ONE 9:e105462

Harasti D, Martin-Smith K, Gladstone W (2014b) Ontogenetic and sex-based differences in habitat preferences and site fidelity of White's seahorse Hippocampus whitei. J Fish Biol 85:1413-1428

Herczeg G, Gonda A, Merilä J (2009) Evolution of gigantism in nine-spined sticklebacks. Evolution 63:3190-3200

Herrel A, Huyghe K, Vanhooydonck B, Backeljau T and others (2008) Rapid large-scale evolutionary divergence in morphology and performance associated with exploitation of a different dietary resource. Proc Natl Acad Sci USA 105:4792-4795

Ho NKP, Ho A, Underwood GD, Underwood A, Zhang D, Lin J (2015) A simple molecular protocol for the identification of hybrid Western Atlantic seahorses, Hippocampus erectus $\times H$. reidi, and potential consequences of hybrids for conservation. J Zoo Aquar Res 3:11-20

Holm S (1979) A simple sequentially rejective multiple test procedure. Scand J Stat 6:65-70

Holthuis LB (1973) Caridean shrimps found in land-locked saltwater ponds at four indo-West Pacific localities (Sinai Peninsula, Funafuti Atoll, Maui and Hawaii Island), with the description of one new genus and four new species. Zool Verh 128:1-48

Hughes AR, Williams SL, Duarte CM, Heck KL Jr, Waycott $M$ (2009) Associations of concern: declining seagrasses and threatened dependent species. Front Ecol Environ 7 : 242-246
Humphreys WF, Watts CHS, Cooper SJB, Leijs R (2009) Groundwater estuaries of salt lakes: buried pools of endemic biodiversity on the western plateau, Australia. Hydrobiologia 626:79-95

Jones AG, Avise JC (2001) Mating systems and sexual selection in male-pregnant pipefishes and seahorses: insights from microsatellite-based studies of maternity. J Hered 92:150-158

Jones AG, Rosenqvist G, Berglund A, Arnold SJ, Avise JC (2000) The Bateman gradient and the cause of sexual selection in a sex-role-reversed pipefish. Proc R Soc Lond B Biol Sci 267:677-680

Jones AG, Moore GI, Kvarnemo C, Walker D, Avise JC (2003) Sympatric speciation as a consequence of male pregnancy in seahorses. Proc Natl Acad Sci USA 100: 6598-6603

KVvarnemo C, Moore GI, Jones AG (2007) Sexually selected females in the monogamous Western Australian seahorse. Proc Biol Sci 274:521-525

Kamichhaney S, Han F, Webster MT, Andersson L, Grant BR, Grant PR (2018) Rapid hybrid speciation in Darwin's finches. Science 359:224-228

* Lazzari MA, Able KW (1990) Northern pipefish, Syngnathus fuscus, occurrences over the Mid-Atlantic Bight continental shelf: evidence of seasonal migration. Environ Biol Fishes 27:177-185

* Lillywhite HB, McCleary RJR (2008) Trophic ecology of insular cottonmouth snakes: review and perspective. $\mathrm{S}$ Am J Herpetol 3:175-185

* Lomolino MV (2005) Body size evolution in insular vertebrates: generality of the island rule. J Biogeogr 32: 1683-1699

KLomolino MV, van der Geer AA, Lyras GA, Palombo MR, Sax DF, Rozzi R (2013) Of mice and mammoths: generality and antiquity of the island rule. J Biogeogr 40:1427-1439

KLosos JB, Ricklefs RE (2009) Adaptation and diversification on islands. Nature 457:830-836

KLourie SA, Pollom RA, Foster SJ (2016) A global revision of the seahorses Hippocampus Rafinesque 1810 (Actinopterygii: Syngnathiformes): taxonomy and biogeography with recommendations for further research. Zootaxa 4146:1-66

MacColl ADC, Nagar AE, de Roij J (2013) The evolutionary ecology of dwarfism in three-spined sticklebacks. J Anim Ecol 82:642-652

Mai ACG, Velasco G (2012) Population dynamics and reproduction of wild longsnout seahorse Hippocampus reidi. J Mar Biol Assoc UK 92:421-427

Manning CG, Foster SJ, Vincent ACJ (2019) A review of the diets and feeding behaviours of a family of biologically diverse marine fishes (Family Syngnathidae). Rev Fish Biol Fish, doi:10.1007/s11160-019-09549-z

* Martin-Smith KM, Vincent ACJ (2005) Seahorse declines in the Derwent estuary, Tasmania in the absence of fishing pressure. Biol Conserv 123:533-545

Masonjones HD (1997) Sexual selection in the dwarf seahorse, Hippocampus zosterae (Syngnathidae): an investigation into the mechanisms determining the degree of male vs. female intrasexual competition and intersexual choice. PhD thesis, Tufts University, Medford, MA

Masonjones HD, Rose E, Mc RAELB, Dixson DL (2010) An examination of the population dynamics of syngnathid fishes within Tampa Bay, Florida, USA. Curr Zool 56: 118-133

McCullough EL, Buzatto BA, Simmons LW (2018) Popula- 
tion density mediates the interaction between pre- and postmating sexual selection. Evolution 72:893-905

Mkare TK, van Vuuren BJ, Teske PR (2017) Conservation implications of significant population differentiation in an endangered estuarine seahorse. Biodivers Conserv 26:1275-1293

Monteiro NM, Berglund A, Vieira MN (2006) Reproductive migrations of the sex role reversed pipefish Nerophis lumbriciformis (Pisces; Syngnathidae). J Fish Biol 69:66-74

Moreau MA, Vincent ACJ (2004) Social structure and space use in a wild population of the Australian short-headed seahorse Hippocampus breviceps Peters, 1869. Mar Freshw Res 55:231-239

Naud MJ, Curtis JMR, Woodall LC, Gaspar MB (2009) Mate choice, operational sex ratio, and social promiscuity in a wild population of the long-snouted seahorse Hippocampus guttulatus. Behav Ecol 20:160-164

Powell AB, LaCroix MW, Cheshire RT (2002) An evaluation of northern Florida Bay as a nursery area for red drum, Sciaenops ocellatus, and other juvenile and small resident fishes. NOAA Tech Memo NMFS-SEFSC-485

Rollins JL (2017) Body-size and growth-rate divergence among populations of threespine stickleback (Gasterosteus aculeatus) in Cook Inlet, Alaska, USA. Can J Zool 95:877-884

Roos G, Van Wassenbergh S, Herrel A, Adriaens D, Aerts P (2010) Snout allometry in seahorses: insights on optimisation of pivot feeding performance during ontogeny. J Exp Biol 213:2184-2193

Roos G, Van Wassenbergh S, Aerts P, Herrel A, Adriaens D (2011) Effects of snout dimensions on the hydrodynamics of suction feeding in juvenile and adult seahorses. J Theor Biol 269:307-317

Rosa IL, Oliveira TPR, Castro ALC, Moraes LE de S and others (2007) Population characteristics, space use and habitat associations of the seahorse Hippocampus reidi (Teleostei: Syngnathidae). Neotrop Ichthyol 5:405-414

Rose E, Small CM, Saucedo HA, Harper C, Jones AG (2014) Genetic evidence for monogamy in the dwarf seahorse, Hippocampus zosterae. J Hered 105:922-927

Rose E, Masonjones HD, Jones AG (2016) A DNA-based assessment of the phylogenetic position of a morphologically distinct, anchialine-lake-restricted seahorse. J Hered 107:553-558

Rosenqvist G, Berglund A (2011) Sexual signals and mating patterns in Syngnathidae. J Fish Biol 78:1647-1661

Sefc KM (2008) Variance in reproductive success and the

Editorial responsibility: Uwe Krumme,

Rostock, Germany opportunity for selection in a serially monogamous species: simulations of the mating system of Tropheus (Teleostei: Cichlidae). Hydrobiologia 615:21-35

Short G, Smith R, Motomura H, Harasti D, Hamilton H (2018) Hippocampus japapigu, a new species of pygmy seahorse from Japan, with a redescription of $H$. pontohi (Teleostei, Syngnathidae). ZooKeys 779:27-49

Silveira RB, Silva JRS (2016) Growing the threatened seahorse Hippocampus erectus Perry 1810 in the laboratory. Int J Oceanogr Mar Biol 3:93-101. https://www.research gate.net/publication/305346513_Growing_the_threatened _seahorse_Hippocampus_erectus_Perry_1810_in_the_ laboratory

Stallings CD, Brower JP, Heinlein Loch JM, Mickle A (2014) Catch comparison between otter and rollerframe trawls: implications for sampling in seagrass beds. Fish Res 155: 177-184

Teixeira RL, Musick JA (2001) Reproduction and food habits of the lined seahorse, Hippocampus erectus (Teleostei: Syngnathidae) of Chesapeake Bay, Virginia. Braz J Biol 61:79-90

Teske PR, Cherry MI, Matthee CA (2004) The evolutionary history of seahorses (Syngnathidae: Hippocampus): molecular data suggest a West Pacific origin and two invasions of the Atlantic Ocean. Mol Phylogenet Evol 30:273-286

Vincent ACJ (1990) Reproductive ecology of seahorses. PhD dissertation, University of Cambridge

Vincent ACJ (1996) The international trade in seahorses. TRAFFIC International, Cambridge

* Vincent ACJ, Foster SJ, Koldewey HJ (2011) Conservation and management of seahorses and other Syngnathidae. J Fish Biol 78:1681-1724

Wilson AB (2009) Fecundity selection predicts Bergmann's rule in syngnathid fishes. Mol Ecol 18:1263-1272

*Wilson AB, Martin-Smith KM (2007) Genetic monogamy despite social promiscuity in the pot-bellied seahorse (Hippocampus abdominalis). Mol Ecol 16:2345-2352

*Woodall LC, Koldewey HJ, Shaw PW (2011) Serial monogamy in the European long-snouted seahorse Hippocampus guttulatus. Conserv Genet 12:1645-1649

Whoodall LC, Otero-Ferrer F, Correia M, Curtis JMR, Garrick-Maidment N, Shaw PW, Koldewey HJ (2018) A synthesis of European seahorse taxonomy, population structure, and habitat use as a basis for assessment, monitoring and conservation. Mar Biol 165:19

Young E (1966) Eleuthera: the island called freedom. Regency Press, London

Submitted: August 20, 2018; Accepted: February 12, 2019 Proofs received from author(s): May 7, 2019 